\title{
ARTICLE Study on Microbial Community Succession and Protein Hydrolysis of Donkey Meat during Refrigerated Storage Based on Illumina NOVA Sequencing Technology
}

OPEN ACCESS

$\begin{array}{ll}\text { Received } & \text { April 12, } 2021 \\ \text { Revised } & \text { May 19, } 2021 \\ \text { Accepted } & \text { June 9, } 2021\end{array}$

*Corresponding author: Guiqin Liu College of Agronomy, Liaocheng University, Liaocheng, China

Tel: +86-0635-8239956

Fax: +86-0635-8239956

E-mail: guiqinliu@1cu.edu.cn

\section{*ORCID}

Zixiang Wei

https://orcid.org/0000-0002-2354-6941

Ruidong Chu

https://orcid.org/0000-0002-0539-6011

Lanjie Li

https://orcid.org/0000-0001-5656-1550

Jingjing Zhang

https://orcid.org/0000-0001-6558-0606

Huachen Zhang

https://orcid.org/0000-0003-3854-6001

Xiaohong Pan

https://orcid.org/0000-0001-9601-3604

Yifan Dong

https://orcid.org/0000-0003-1310-520X

Guiqin Liu

https://orcid.org/0000-0002-6230-9885

\author{
Zixiang Wei ${ }^{1}$, Ruidong Chu ${ }^{2}$, Lanjie $\mathrm{Li}^{2}$, Jingjing Zhang ${ }^{3}$, Huachen Zhang ${ }^{2}$, \\ Xiaohong Pan ${ }^{2}$, Yifan Dong ${ }^{2}$, and Guiqin Liu, ${ }^{2, *}$ \\ ${ }^{1}$ Institute of Bio-Pharmaceutical, Liaocheng University, Liaocheng, China \\ ${ }^{2}$ College of Agronomy, Liaocheng University, Liaocheng, China \\ ${ }^{3}$ College of Life and Health Science, Camerino University, Camerino, Italy
}

\begin{abstract}
In this study, the microbial community succession and the protein hydrolysis of donkey meat during refrigerated $\left(4^{\circ} \mathrm{C}\right)$ storage were investigated. 16S rDNA sequencing method was used to analyze the bacteria community structure and succession in the level of genome. Meanwhile, the volatile base nitrogen (TVB-N) was measured to evaluate the degradation level of protein. After sorting out the sequencing results, 1,274,604 clean data were obtained, which were clustered into 2,064 into operational taxonomic units (OTUs), annotated to 32 phyla and 527 genus. With the prolonging of storage time, the composition of microorganism changed greatly. At the same time, the diversity and richness of microorganism decreased and then increased. During the whole storage period, Proteobacteria was the dominant phyla, and the Photobacterium, Pseudompnas, and Acinetobacter were the dominant genus. According to correlation analysis, it was found that the abundance of these dominant bacteria was significantly positively correlated with the variation of TVB-N. And Pseudomonas might play an important role in the production of TVB-N during refrigerated storage of donkey meat. The predicted metabolic pathways, based on PICRUSt analysis, indicated that amino metabolism in refrigerated donkey meat was the main metabolic pathways. This study provides insight into the process involved in refrigerated donkey meat spoilage, which provides a foundation for the development of antibacterial preservative for donkey meat.
\end{abstract}

Keywords donkey meat, refrigerated storage, bacteria, community succession, Illumina NOVA sequencing technology

\section{Introduction}

In recent years, donkey meat has been increasingly favored because of its high protein, low fat and tender meat characteristics (Cocolin et al., 2013; Polidori et al., 2008). However, these characteristics provide a rich substrate for the growth of

(C) Korean Society for Food Science of Animal Resources. This is an open access article distributed under the terms of the Creative Commons Attribution Non-Commercial License (http://creativecommons.org/licences/by-nc/3.0) which permits unrestricted non-commercial use, distribution, and reproduction in any medium, provided the original work is properly cited. 
microorganisms, which leads to the deterioration of fresh donkey meat. Refrigerated storage is a common method of inhibiting microbial growth among varieties of preservation techniques. Numerous studies on refrigerated storage of meats have been reported (Ercolini et al., 2011; Giannuzzi et al., 1998; Marino et al., 2015; Wang et al., 2019). However, little information on refrigerated donkey meat is available. Therefore, studying the microbial community succession in donkey meat during refrigerated storage is important for preventing meat putrefaction and extending the shelf life.

Traditional cultivation methods and molecular techniques, such as real-time quantitative PCR (qRT-PCR), denaturing gradient gel electrophoresis (DGGE) and temperature gradient gel electrophoresis (TGGE), were used to investigate the composition of microbial communities in meat (Ercolini et al., 2013; Van Reckem et al., 2021). However, the information obtained from these methods was limited, and could not reflect the changes of microorganism comprehensively (You et al., 2016). Recently, Illumina NOVA sequencing technology based on the 16S rDNA has been used to analyze the composition of microorganisms (Cao et al., 2021; Pfaffl and Riedmaier-Sprenzel, 2018). The result showed that white muscles were dominated by Aeromonas in the early storage period, and dark muscles were dominated by Aeromonas, Pseudomonas and Lactococcus. And Pseudomonas was the dominant species in the two kinds of different color muscles after corruption (Li et al., 2018). The microbial population changed significantly during storage, among which Micrococcaceae and Flavobacteriaceae occupied the absolute dominance in the later period (Zhao et al., 2015). Nevertheless, the application of this method to refrigerated donkey meat has not been reported. In this study, bacterial community dynamics were investigated in donkey meat during refrigerated storage by Illumina NOVA sequencing technology. The volatile base nitrogen (TVB-N) was measured to evaluate the degradation level of protein. The purpose of this study was to reveal the relationship between spoilage and bacterial community composition, identify the metabolic function of donkey meat during refrigerated storage, and explain different spoilage characteristics from the perspective of microbial metabolic function.

\section{Materials and Methods}

\section{Sample preparation}

The sampling method was referred to Zhang with slightly modificated (Zhang et al., 2018). Fresh donkey meat from the longissimus of 2-year-old male Dezhou donkey were purchased from Dong-E-E-Jiao (Liaocheng, China), then stored in a sterile crisper at $4^{\circ} \mathrm{C}$ which covered the seal with sterilized polyethylene plastic wrap immediately. Samples of refrigerated donkey meat were taken from the same fillet every 2 days for microbial analysis and quality analysis. The experiment was set in four parallel settings.

\section{Measurement of TVB-N}

The TVB-N content was measured with $10 \mathrm{~g}$ of samples according to the national standard method (GB/T 5009.22-2016). The value expressed as mg TVB-N per $100 \mathrm{~g}$ of meat and was measured in triplicate.

\section{DNA extraction}

Extraction of bacterial DNA followed the procedure of Xiao with some modifications (Xiao et al., 2013). Twenty-five grams of donkey meat sample was cut up and mixed with $50 \mathrm{~mL}$ sterile saline, and then centrifuged at 3,000×g for $10 \mathrm{~min}$. Then the supernatant was centrifuged again at $12,000 \times \mathrm{g}$ for $10 \mathrm{~min}$. After that, the supernatant was removed and the precipitate was washed with $1.0 \mathrm{~mL}$ sterile water. DNA extraction kit (Qiagen 51604) was used to extract bacterial DNA 
from the precipitation mixture. Three parallel DNA from the same donkey meat sample and storage conditions were mixed together. The DNA extraction was stored at $-60^{\circ} \mathrm{C}$ for further analysis.

\section{S rRNA gene amplification}

PCR amplicons were obtained from the V3-V4 regions of the 16S rRNA gene and analyzed for bacterial diversity on the Illumina NovaSeq PE250 platform. Sequencing primers for PCR amplification were 515F (GTGCCAGCMGCCGC GGTAA) and 806R (GGACTACHVGGGTWTCTAAT) with the following protocol: $98^{\circ} \mathrm{C}$ for 5 min, followed by 27 cycles at $98^{\circ} \mathrm{C}$ for $30 \mathrm{~s}, 56^{\circ} \mathrm{C}$ for $30 \mathrm{~s}$, and $68^{\circ} \mathrm{C}$ for $60 \mathrm{~s}$ and a final extension at $72^{\circ} \mathrm{C}$ for $7 \mathrm{~min}$. The amplified PCR products were detected by $2 \%$ agarose gel electrophoresis and purified using the Gene JET Genomic DNA Purification Kit. Each sample was analyzed in triplicate.

\section{Sequencing and data processing}

QuantiFluor-ST (Promega, Madison, WI, USA) was used to quantify the PCR products, and the TruSeq ${ }^{\circledR}$ DNA PCR-Free Sample Preparation Kit was used to build sequencing libraries. The library was paired-end sequenced by using the Illumina NovaSeq6000 system (Illumina, San Diego, CA, USA). Paired and clean dates were merged using FLASH (V1.2.7, http://ccb.jhu.edu/software/FLASH/) and filtered by Qiimer (V1.9.1, http://qiime.org/scripts/split_libraries_fastq.html) with a removal of syncyte sequence (https://github.com/torognes/vsearch/) (Bokulich et al., 2013; Caporaso et al., 2010; Magoč et al., 2011). Effective tags with $97 \%$ similarity were clustered into OTUs cluster using UPARSE (v7.0.1001, http://www.drive5.com/ uparse/) (Haas et al., 2011). Based on Mothur (v1.39.1, https://www.mothur.org/) and SILVA Database (https://www.arbsilva.de/), the representative sequences from each OTU were annotated as species (confidence interval 0.8-1.0), to obtain the microbial composition of different samples at various taxonomic levels (Edgar et al., 2013). QIIME v1.9.1 was used to measure bacterial richness and diversity using alpha-diversity indexes such as Good's coverage, Chao 1, ACE, Shannon index, and Simpson's index (Kemp et al., 2004). Tukey test was used to determine the significance of differences in Alpha diversity index. To analyze the difference in bacterial community composition of samples, beta-diversity analysis including principe component analysis (PCA), multi response permutation procedure (MRPP), and linear discriminant analysis effect size (LEFSe) was performed. The differential bacteria were defined by the conditions (LEFSE, $\mathrm{p}>0.05$ and LDA $>2$, Metastats, $\mathrm{p}<0.05$ and $\mathrm{Q}<0.1$ with relative abundance $>10^{-3}$ ) ( $\mathrm{Ji}$ et al., 2019). Vegan software in $\mathrm{R}$ software (v.3.1.1) was used to analyze non-metric multidimensional scaling (NMDS) two-dimensional graph at non-metric scale (Liu et al., 2019).

\section{Statistical analysis}

Correlation between microbiota and TVB-N during storage times was analyzed using IBM SPSS Statistics 20. Significance was defined as $\mathrm{p}<0.05$.

\section{Results and Discussion}

\section{Analysis of bacterial community diversity}

A total of 1,058,807 high-quality valid sequences were obtained through quality control and integration of the original sequences of each sample (Table 1). The length of these sequences ranged from 400 to $450 \mathrm{bp}$ on average. A minimum similarity threshold of $97 \%$ was used to produce $221-869$ OTUs per sample. The ACE and Chaol indexes followed the same 
Table 1. Analysis of $\alpha$ diversity indexes of refrigerated donkey meat in different storage times

\begin{tabular}{lccccc} 
Store time & $0 \mathrm{~d}$ & $2 \mathrm{~d}$ & $4 \mathrm{~d}$ & $6 \mathrm{~d}$ & $7 \mathrm{~d}$ \\
OTUs & $869.0^{\mathrm{Aa}}$ & $868.3^{\mathrm{Aa}}$ & $221.5^{\mathrm{B}}$ & $357.0^{\mathrm{B}}$ & $454.3^{\mathrm{Bb}}$ \\
Chao1 & $900.65^{\mathrm{AC}}$ & $888.22^{\mathrm{C}}$ & $216.4^{\mathrm{B}}$ & $368.34^{\mathrm{ABC}}$ & $439.72^{\mathrm{ABC}}$ \\
ACE & $928.33^{\mathrm{AC}}$ & $950.93^{\mathrm{C}}$ & $247.51^{\mathrm{B}}$ & $400.33^{\mathrm{ABC}}$ & $487.31^{\mathrm{ABC}}$ \\
Shannon & $4.485^{\mathrm{A}}$ & $3.198^{\mathrm{B}}$ & $1.344^{\mathrm{C}}$ & $1.932^{\mathrm{BC}}$ & $2.062^{\mathrm{BC}}$ \\
Simpson & $0.853^{\mathrm{AC}}$ & $0.713^{\mathrm{A}}$ & $0.493^{\mathrm{B}}$ & $0.597^{\mathrm{BC}}$ & $0.623^{\mathrm{BC}}$ \\
Good's coverage (\%) & 99.5 & 99.5 & 99.9 & 99.8 & 99.7 \\
\hline
\end{tabular}

${ }^{A-C}$ Different letters in the same row represent significant differences $(\mathrm{p}<0.05)$.

OTU, operational taxonomic units.

pattern as the OUT numbers, decreasing first and then rising, which was consistent with previous findings (Zheng et al., 2020). The results showed that the Good's coverage rate of all samples were above $99.5 \%$, which indicated that nearly all bacteria in the samples could be identified at the present sequencing level. At the end of the storage time, the values of Chao 1, ACE, Shannon and Simpson indexes (d7) were significantly lower than the initial values $(\mathrm{d} 0)(\mathrm{p}<0.05)$, suggested that a subset of bacteria became dominant in samples, which are similar to the variation of microbial community Alpha diversity during the storage of chilled pork (Zhou et al., 2020).

\section{Composition of bacterial community}

A total of 32 phyla were identified in the sequencing analysis, including Proteobacteria, Firmicutes, Bacteroidetes, Acidobacteria, Actinobacteria, and Cyanobacteria (Fig. 1A). Proteobacteria and Firmicutes were the major phyla during storage, accounting for $84 \%$ of all OTUs, which were consistent with poultry, livestock and aquatic products (Hou et al., 2021; Li et al., 2018; Li et al., 2019a; Saewa et al., 2021), which indicated that there is no distinction between species. With the extension of storage time, the proportion of Proteobacteria in each sample rose from $74.10 \%$ to $97.10 \%$, and the proportion of Firmicutes dropped from $10.20 \%$ to $1.40 \%$. There seemed to be no significant difference in microbial communities in different storage times with Proteobacteria and Firmicutes predominanted. These results indicated that Proteobacteria and Firmicutes might be the main bacteria phyla in the process of meat spoilage in cold storage, which played an important role in the quality change.

Bacterial community dynamics were evaluated based on changes in relative abundance at genus level during storage (Fig. 1B). A total of 527 bacteria genera were identified by the sequencing analysis, including Pseudomonas, Photobacterium, Acinetobacter, Exiguobacterium, and Brevundimonas. As the storage time increased, Photobacterium showed a trend of decreasing first and then increasing, but Pseudomonas was the dominant bacteria which are consistent with the experimental results of Yang (Yang et al., 2018). Related research reports showed that Pseudomonas were common spoilage bacterias in the process of low temperature storage of meat products, with strong production ammonia and other putrefaction products (Shaw and Latty, 1982). In meat storage, Pseudomonas could become the dominant genus mainly because it could decompose and utilize protein (Doulgeraki and Nychas, 2013).

A genus-level clustering heatmap based on the top 35 genera in relative abundance was constructed to analyze and compare the composition and dynamic changes of microbial communities in different samples (Fig. 2). The heatmap showed that the relative abundance of different bacterial communities in each time period changed greatly. The redder and the greener illustrated the higher and the lower relative abundance, respectively. Due to the abundance of nutrients, microorganisms 

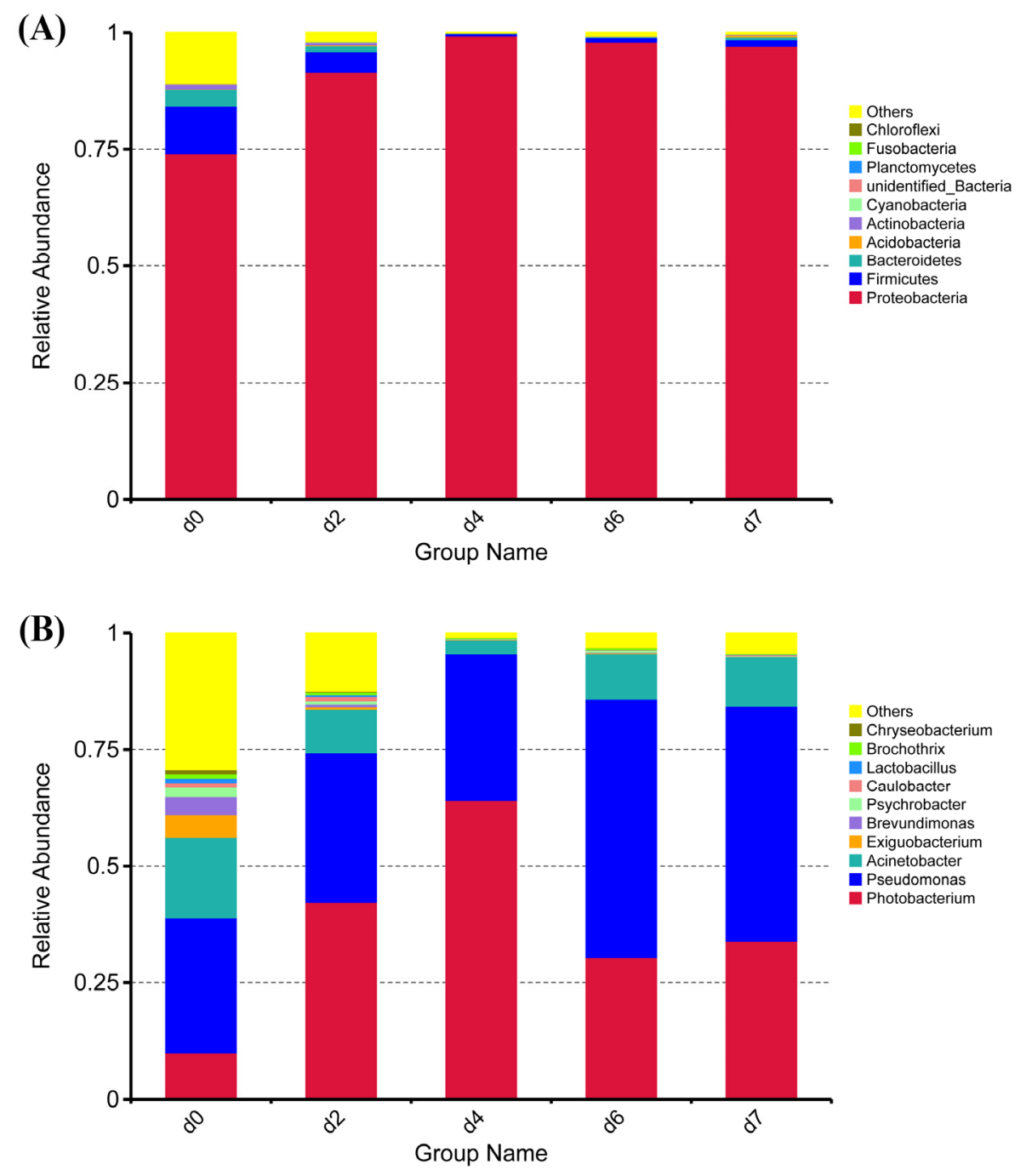

Fig. 1. Accumulation map of phyla (A) and genera (B) abundances of microbiota during storage times of refrigerated donkey meat.

multiply rapidly and their diversity increased at the beginning of storage. However, it showed a certain degree of stability between 4 and 7 days. As the storage time increased, Photobacterium showed a trend of decreasing, which became the dominant bacterium (d4). At the end of the storage, Pseudomonas and Acinetobacter increased, then became the dominant bacterium with Photobacterium. The relative abundance of Acidisoma, Granulicella, and Shewanella increases as well. There was a significant difference in the relative abundance of each genus between the early storage and the late storage in the heatmap. Shewanella mostly came from the spoilage of fish and shrimp meat (Lund et al., 2000). Acidisoma had a relatively high relative abundance, but the relative abundance was only $0.2 \%$ on the 7 th day, so it does not contribute much to the deterioration of donkey meat. Therefore, it is not a kind of typical metamorphic bacteria in donkey meat. Acidisoma belongs to Alpha proteobacteria that were metabolized by chemical energy (Belova et al., 2009). The result indicated that it could be metabolized by carbohydrates and organic acids. The increase in relative abundance on the 7 th day was probably due to the hydrolysis of fat in donkey meat.

In summary, the study found that with the prolong of storage time, Pseudomonas, Photobacterium and Acinetobacter were the characteristic spoilage bacteria in donkey meat. The relative abundance of dominant bacteria in refrigerated donkey meat was dynamically changing, but the dominant bacteria category was not changed. 


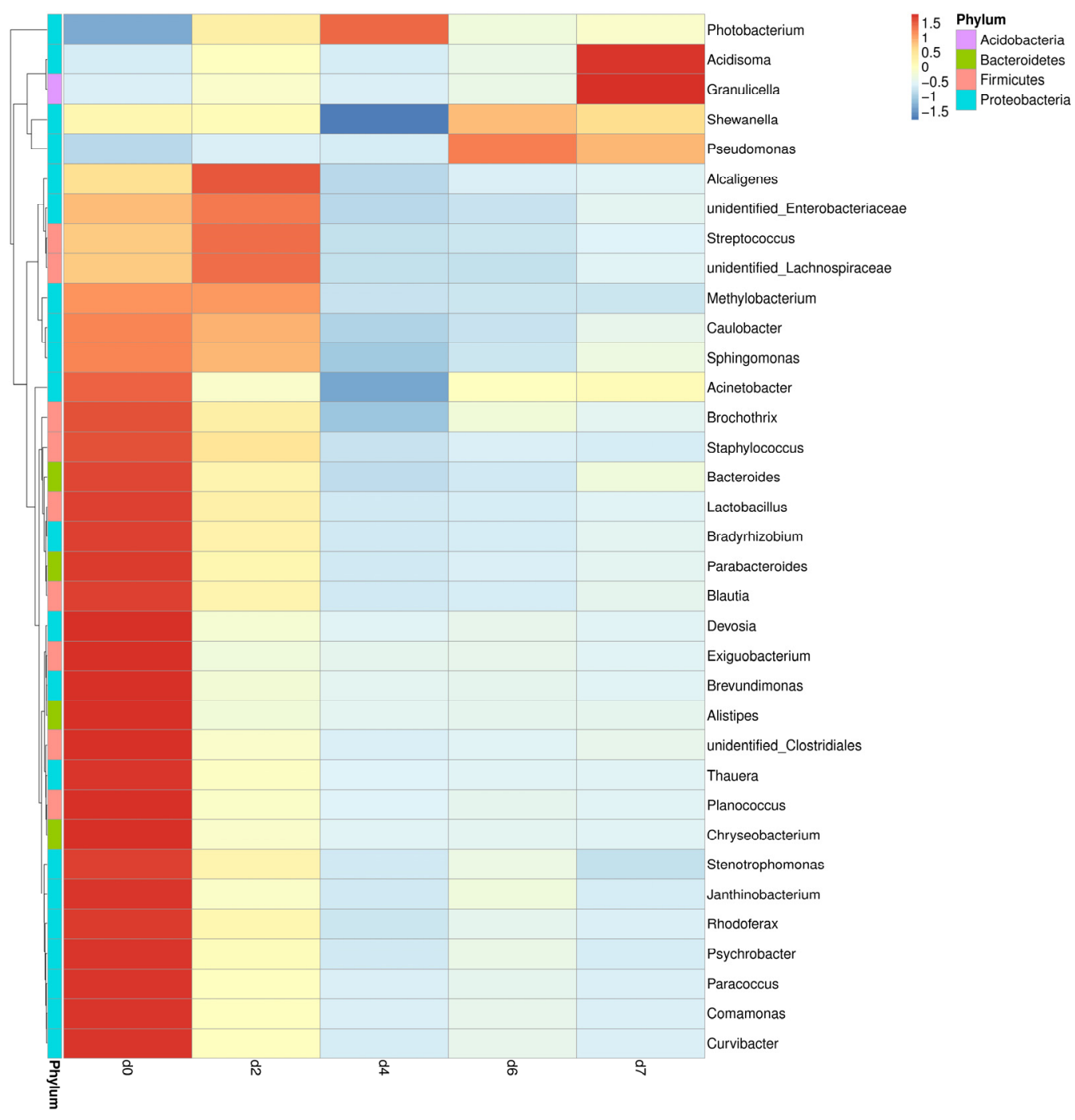

Fig. 2. The heat map of relative abundance of microflora of refrigerated donkey meat in different storage times based on the genus level.

\section{Analysis of microbial community differences}

NMDS two-dimensional graph at non-metric scale was constructed to analyze the differences of bacterial communities during storage times (Fig. 3). The closer the distance between the coordinate axes, the higher the composition similarity between the samples. In the early storage ( $\mathrm{d} 0$ and $\mathrm{d} 2)$, the aggregation was the highest, which indicated that the bacterial community structure of the samples in the early stage of storage was relatively similar. With the prolong of storage time, the composition of microorganisms in the samples increased. There were significant differences in community structure between early storage $(\mathrm{d} 0$ and $\mathrm{d} 2)$ and late storage $(\mathrm{d} 6$ and $\mathrm{d} 7)(\mathrm{p}<0.05)$. However, there was no significant difference in early and late storage. Similar conclusions were supported from analysis of chilled beef from different sources (Säde et al., 2017). This indicated that there was not enough superiority between microbiota in the early stage, but the microbiota in the later stage were gradually replaced by the dominant bacteria, which may be related to the influence of $\mathrm{pH}$ and secondary metabolites on the flora structure (Ingram and Dainty, 1971).

Bacteria with significant differences (relative abundance $>10^{-3}$ ) were counted to analyze the differences of bacterial communities at different storage times (Table 2). In order to further explore the dominant microbial species, which caused the deterioration of donkey meat, the bacteria genera with relative abundance $>10^{-3}$ were selected as the research object (Li et al., 


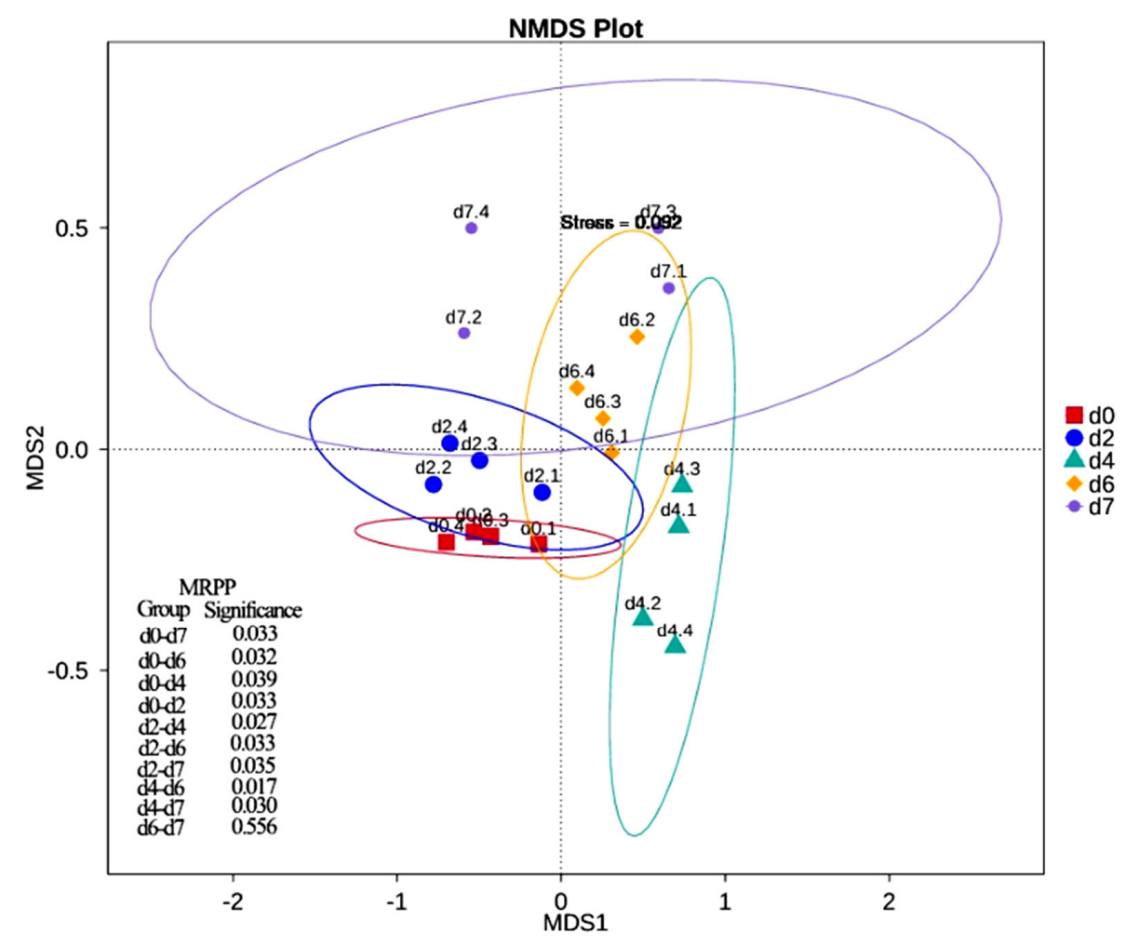

Fig. 3. Significant analysis of microbial difference of refrigerated donkey meat in different storage times.

Table 2. Significant analysis of bacteria during storage of donkey meat $\left(\times 10^{-3}\right)$

\begin{tabular}{|c|c|c|c|c|c|}
\hline \multirow{2}{*}{ Genus } & \multicolumn{5}{|c|}{ Store time } \\
\hline & $0 \mathrm{~d}$ & $2 \mathrm{~d}$ & $4 \mathrm{~d}$ & $6 \mathrm{~d}$ & $7 \mathrm{~d}$ \\
\hline Photobacterium & $9.9^{\mathrm{A}}$ & $42.3^{\mathrm{CB}}$ & $64^{\mathrm{B}}$ & $33.8^{\mathrm{C}}$ & $30.4^{\mathrm{C}}$ \\
\hline Pseudomonas & $29.2^{\mathrm{A}}$ & $32.1^{\mathrm{AC}}$ & $31.5^{\mathrm{AC}}$ & $55.4^{\mathrm{B}}$ & $50.5^{\mathrm{BC}}$ \\
\hline Acinetobacter & $17.2^{\mathrm{A}}$ & $9.2^{\mathrm{B}}$ & $3.1^{\mathrm{C}}$ & $9.8^{\mathrm{B}}$ & $10.5^{\mathrm{B}}$ \\
\hline Brevundimonas & $3.9^{\mathrm{A}}$ & $0.5^{\mathrm{AB}}$ & $0.05^{\mathrm{B}}$ & $0.1^{\mathrm{B}}$ & $0.04^{\mathrm{B}}$ \\
\hline Psychrobacter & $2^{\mathrm{A}}$ & $0.7^{\mathrm{AB}}$ & $0.1^{\mathrm{B}}$ & $0.4^{\mathrm{B}}$ & $0.2^{\mathrm{B}}$ \\
\hline
\end{tabular}

${ }^{A-C}$ Different letters in the same row represent significant differences $(\mathrm{p}<0.05)$.

2019b). The significant differences in the storage time were shown in Table 2 . The d0 of Photobacterium spp. was extremely significantly lower than other times $(\mathrm{p}<0.01)$, the fourth peak reached the highest, and $\mathrm{d} 4$ was extremely significantly higher than $\mathrm{d} 6$ or $\mathrm{d} 7(\mathrm{p}<0.01)$. Pseudomonas $\mathrm{d} 0$ was extremely significantly lower than $\mathrm{d} 6$ or $\mathrm{d} 7(\mathrm{p}<0.01)$, d6 was extremely significantly higher than $\mathrm{d} 2$ or $\mathrm{d} 4(\mathrm{p}<0.01)$, the difference was not significant at other times. The study of Wang also obtained the similar results (Wang et al., 2014). Acinetobacter was extremely significantly higher in $\mathrm{d} 0$ than other times $(\mathrm{p}<0.01)$. However, it was extremely significant lower in $\mathrm{d} 4$ than other times $\mathrm{d} 4(\mathrm{p}<0.01)$, Brevundimonas and Psychrobacterium were extremely noteworthy significant higher in $\mathrm{d} 0$ than $\mathrm{d} 4, \mathrm{~d} 6$, and $\mathrm{d} 7(\mathrm{p}<0.01)$. Some studies reported that Pseudomonas was the main microorganism that caused meat spoilage under aerobic cold storage (Parlapani et al., 2015; Stellato et al., 2017; Wang et al., 2021). At the same time, Acinetobacter, Brevundimonas, and Psychrobacter cannot form influential competition with them (Mohareb et al., 2015; Rodríguez-Calleja et al., 2005). In this study, the increased number of Photobacterium and Pseudomonas showed that the microbial community had undergone tremendous changes during storage. It may be very 
important to control the growth of Photobacterium and Pseudomonas for prolonging the shelf-life of donkey meat in a specific storage period.

\section{Prediction of microbial metabolic function}

The number of microbial metabolic pathways and the relative abundance of metabolic pathways determine the speed and extent of the deterioration of meat products. The prediction of homologous protein clusters of functional genes by using the PICRUSt was used to analyze the changes of microbial metabolic function in refrigerated donkey meat in different storage times (Fig. 4, Fig. 5). The screening identified 10 pathways related to metabolism. Except for fat metabolism, all metabolic pathways were significantly different at the end of storage (d7) and the beginning of storage $(d 0)(p<0.05)$. During the entire storage process, the relative abundance of amino acid metabolism and carbohydrate metabolism accounted for a high proportion, which was consistent with previous studies (Li et al., 2019a). Donkey meat had the highest proportion of amino acid metabolism in bacterial flora, which might be due to the high protein content of donkey meat. Stellato et al. (2016) found that the proportion of amino acid metabolism in each metabolic function was the main function in pork and beef. Metabolic pathways were gathered in 2 clusters together with late storage ( $\mathrm{d} 6$ and $\mathrm{d} 7$ ) and or mid-term (d2 and $\mathrm{d} 4$ ), which might be caused by the bacterial diversity decreases in late cold storage period. The result also found that the relative abundance of amino acid and fat metabolism increased during storage prolonged. Ercolini et al. (2010) reported that Pseudomonas had strong lipid and protein hydrolysis, which had the highest relative abundance in the late storage period. Furthermore, the relationship between different bacterial genera and metabolic pathways were also analyzed. Glucose and lactic acid were used up by Pseudomonas firstly, and then the protein started to be consumed (Nychas et al., 2008). Combined with the Fig. 6, Pseudomonas was significantly positively correlated with amino acid metabolism, which was consisted with the increase of relative abundance (Fig. 1B) and amino acid metabolism (Fig. 5) of Pseudomonas in late period (d6 and d7).

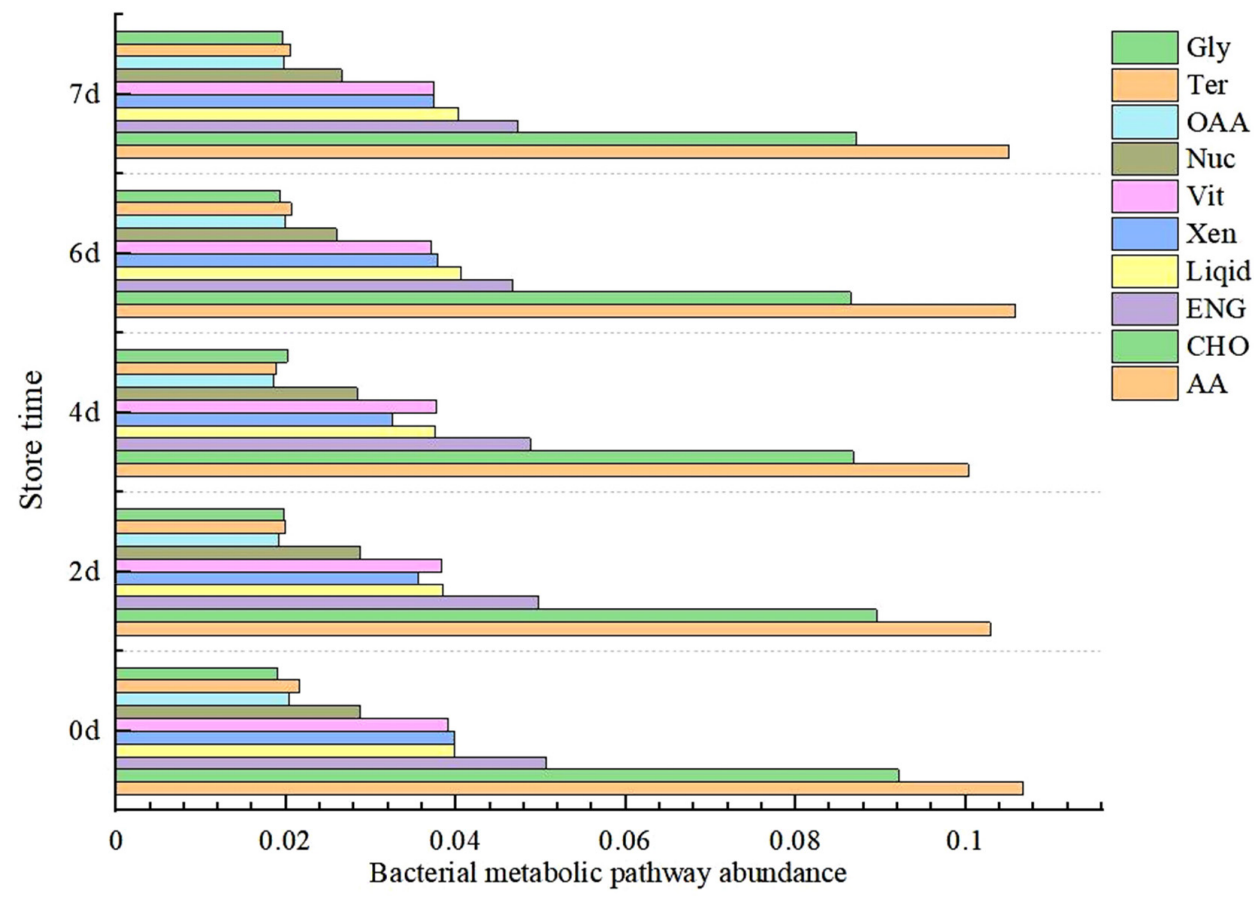

Fig. 4. Relative abundance of bacteria predicted metabolic pathway during storage. 


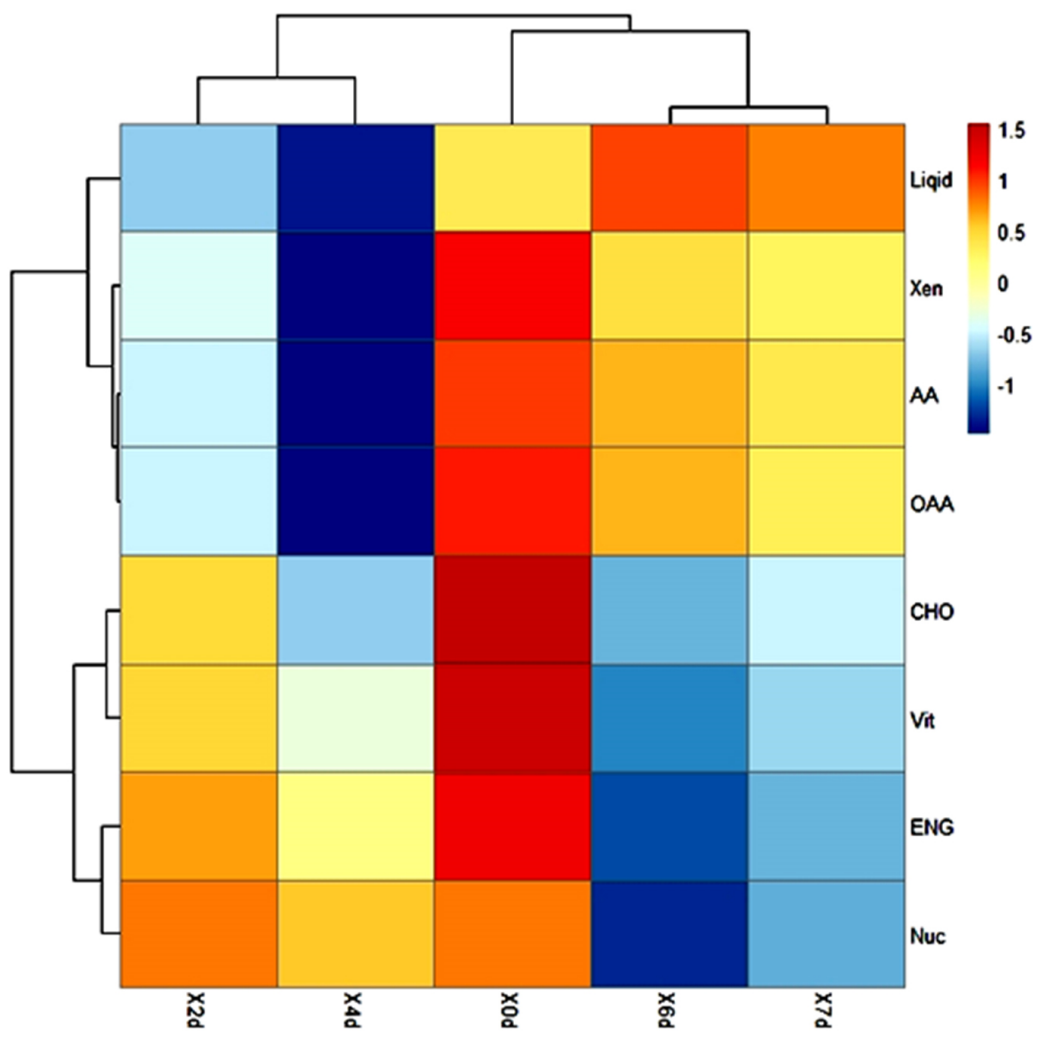

Fig. 5. The heat map of microbial metabolic pathway of refrigerated donkey meat in different storage times.

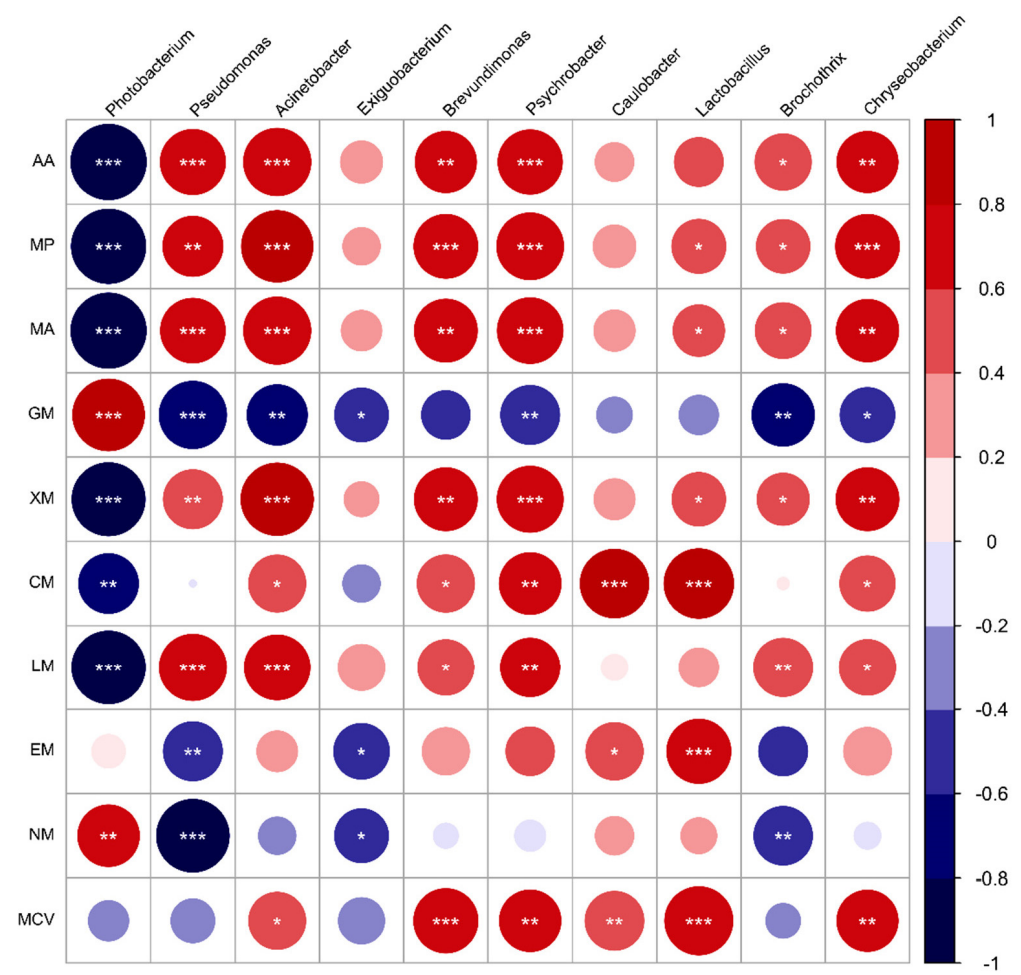

Fig. 6. The heat map of bacterial metabolic pathways of frozen donkey meat (Correlation coefficient matrix of bacterial genus and metabolic pathway was obtained by SPSS partial correlation analysis, and heat map was drawn by $R$ software (v.3.1.1). Red represents positive correlation, blue represents negative correlation, circle color depth and size represent correlation. ${ }^{*} p<0.05,{ }^{* *} p<0.01,{ }^{*} p<0.001$. 


\section{Correlation analysis of TVB-N and microorganisms}

The volatile base nitrogen (TVB-N) is the total amount of nitrogen extracted from the aqueous extract of meat or meat products (under alkaline conditions), which produced by the effects of decarboxylation and deamination caused by microbial reproduction in meat (Lee et al., 2018). It is an important index to evaluate the freshness of meat and meat products. And it is stipulated that TVB-N of fresh (frozen) livestock and poultry products should be less than $15 \mathrm{mg} / 100 \mathrm{~g}$ in China.

The TVB-N content was detected to analyze the changes of refrigerated donkey meat in storage period (Table 3). The results indicated that the content of TVB-N increased significantly with the storage time extend $(\mathrm{p}<0.05)$. The donkey meat was edible within 4 days, after that began to rot and deteriorate. After 7 days of storage, the content of TVB-N reached 18.32 $\mathrm{mg} / 100 \mathrm{~g}$, which was far above edible standards (Maršićlučić et al., 2008). TVB-N with the extension of time maybe was caused by nitrogen-containing substances degradation, such as proteins into amines and ammonia substances, which caused by endogenous enzymes and bacteria (Duan et al., 2019; Kulawik et al., 2013). At the early stage of storage, the content of TVB-N was $7.16 \mathrm{mg} / 100 \mathrm{~g}$, different from that of pork and beef, which might be related to different meat varieties (Cai et al., 2011; Li et al., 2019c).

Pearson correlation analysis was performed on the relative abundance of TOP 10 bacteria genus, and TVB-N content using SPSS in different storage times (Table 4). A total of 7 genera bacterial were screened which were significantly correlated with TVB-N $(\mathrm{p}<0.05)$. There was a significant positive correlation between Pseudomonas and TVB-N content. Pseudomonas might play an important role in the production of TVB-N during cryopreservation of donkey meat (Liang et al., 2021; Na et al., 2018).

\section{Conclusion}

This study was conducted to reveal the microbial community succession and protein hydrolysis of donkey meat during refrigerated storage with Illumina NOVA sequencing technology. A total of 527 bacteria genera were identified by the sequencing analysis, and Photobacterium and Pseudomonas were the dominated microorganisms at late storage. The prediction of homologous protein clusters of functional genes predicted that the carbohydrate metabolism and amino metabolism were the major metabolism in refrigerated donkey meat in different storage times. Pearson correlation analysis indicated that Pseudomonas might play an important role in the production of TVB-N during refrigerated storage of donkey

\section{Table 3. Analysis of TVB-N in donkey meat during storage}

\begin{tabular}{lc}
\hline Store time $(\mathrm{d})$ & TVB-N $(\mathrm{mg} / 100 \mathrm{~g})$ \\
0 & $7.16 \pm 0.29^{\mathrm{h}}$ \\
1 & $8.28 \pm 0.48^{\mathrm{g}}$ \\
2 & $9.67 \pm 0.50^{\mathrm{f}}$ \\
3 & $10.95 \pm 0.95^{\mathrm{e}}$ \\
4 & $13.89 \pm 0.45^{\mathrm{d}}$ \\
5 & $15.14 \pm 1.26^{\mathrm{c}}$ \\
6 & $17.27 \pm 1.04^{\mathrm{b}}$ \\
7 & $18.32 \pm 1.73^{\mathrm{a}}$ \\
\hline
\end{tabular}

Values are mean $\pm \mathrm{SD}$ of 3 replicate.

${ }^{a-h}$ Different letters in the same row represent significant differences $(p<0.05)$. 
Table 4. Correlation between TVB-N content and microbiota genera level

\begin{tabular}{lcc}
\hline Genus & p-value & r-value \\
Photobacterium & 0.14 & 0.34 \\
Pseudomonas & $<0.01$ & 0.74 \\
Acinetobacter & 0.15 & -0.35 \\
Exiguobacterium & 0.06 & -0.43 \\
Brevundimonas & $<0.01$ & -0.65 \\
Psychrobacter & $<0.01$ & -0.73 \\
Caulobacter & 0.01 & -0.52 \\
Lactobacillus & $<0.01$ & -0.56 \\
Brochothrix & 0.01 & -0.52 \\
Chryseobacterium & $<0.01$ & -0.68 \\
\hline
\end{tabular}

meat. Our study deepened the understanding of the microbial decay mechanism of refrigerated donkey meat, and provided theoretical support for the development of donkey meat preservation technology in the later period.

\section{Conflicts of Interest}

The authors declare no potential conflicts of interest.

\section{Acknowledgements}

This study was supported by Shandong Donkey Industry Technology Collaborative Innovation Center (No. SDAIT-27) and Science and Technology Innovation Plan Project of Liaocheng University (No. cxcy2019y150).

\section{Author Contributions}

Conceptualization: Liu G. Data curation: Wei Z, Chu R. Formal analysis: Wei Z, Pan X, Dong Y. Methodology: Li L. Software: Wei Z. Validation: Liu G, Li L. Investigation: Wei Z. Writing - original draft: Wei Z, Li L. Writing - review \& editing: Wei Z, Chu R, Li L, Zhang J, Zhang H, Pan X, Dong Y, Liu G.

\section{Ethics Approval}

This article does not require IRB/IACUC approval because there are no human and animal participants.

\section{References}

Belova SE, Pankratov TA, Detkova EN, Kaparullina EN, Dedysh SN. 2009. Acidisoma tundrae gen. nov., sp. nov. and Acidisoma sibiricum sp. nov., two acidophilic, psychrotolerant members of the Alphaproteobacteria from acidic northern wetlands. Int J Syst Evol Microbiol 59:2283-2290. 
Bokulich NA, Subramanian S, Faith JJ, Gevers D, Gordon JI, Knight R, Mills DA, Caporaso JG. 2013. Quality-filtering vastly improves diversity estimates from Illumina amplicon sequencing. Nat Methods 10:57-59.

Cai J, Chen Q, Wan X, Zhao J. 2011. Determination of total volatile basic nitrogen (TVB-N) content and Warner-Bratzler shear force (WBSF) in pork using Fourier transform near infrared (FT-NIR) spectroscopy. Food Chem 126:1354-1360.

Cao H, Yan Y, Wang L, Dong L, Pang X, Tang S, Li A, Xiang A, Zhang L, Zheng B. 2021. High-throughput sequencing reveals bacterial diversity in raw milk production environment and production chain in Tangshan city of China. Food Sci Anim Resour 41:452-467.

Caporaso JG, Kuczynski J, Stombaugh J, Bittinger K, Bushman FD, Costello EK, Fierer N, Peña AG, Goodrich JK, Gordon JI, Huttley GA, Kelley ST, Knights D, Koenig JE, Ley RE, Lozupone CA, McDonald D, Muegge BD, Pirrung M, Reeder J, Sevinsky JR, Turnbaugh PJ, Walters WA, Widmann J, Yatsunenko T, Zaneveld J, Knight R. 2010. QIIME allows analysis of high-throughput community sequencing data. Nat Methods 7:335-336.

Cocolin L, Alessandria V, Dolci P, Gorra R, Rantsiou K. 2013. Culture independent methods to assess the diversity and dynamics of microbiota during food fermentation. Int J Food Microbiol 167:29-43.

Doulgeraki AI, Nychas GJE. 2013. Monitoring the succession of the biota grown on a selective medium for pseudomonads during storage of minced beef with molecular-based methods. Food Microbiol 34:62-69.

Duan S, Zhou X, Xiao H, Miao J, Zhao L. 2019. Characterization of bacterial microbiota in tilapia fillets under different storage temperatures. J Food Sci 84:1487-1493.

Edgar RC. 2013. UPARSE: Highly accurate OTU sequences from microbial amplicon reads. Nat Methods 10:996-998.

Ercolini D. 2013. High-throughput sequencing and metagenomics: Moving forward in the culture-independent analysis of food microbial ecology. Appl Environ Microbiol 79:3148-3155.

Ercolini D, Casaburi A, Nasi A, Ferrocino I, Di Monaco R, Ferranti P, Mauriello G, Villani F. 2010. Different molecular types of Pseudomonas fragi have the same overall behaviour as meat spoilers. Int J Food Microbiol 142:120-131.

Ercolini D, Ferrocino I, Nasi A, Ndagijimana M, Vernocchi P, La Storia A, Laghi L, Mauriello G, Guerzoni ME, Villani F. 2011. Monitoring of microbial metabolites and bacterial diversity in beef stored under different packaging conditions. Appl Environ Microbiol 77:7372-7381.

Giannuzzi L, Pinotti A, Zaritzky N. 1998. Mathematical modelling of microbial growth in packaged refrigerated beef stored at different temperatures. Int J Food Microbiol 39:101-110.

Haas BJ, Gevers D, Earl AM, Feldgarden M, Ward DV, Giannoukos G, Ciulla D, Tabbaa D, Highlander SK, Sodergren E, Methé B, DeSantis TZ, Petrosino JF, Knight R, Birren BW. 2011. Chimeric 16S rRNA sequence formation and detection in Sanger and 454-pyrosequenced PCR amplicons. Genome Res 21:494-504.

Hou W, Yue Q, Liu W, Wu J, Yi Y, Wang H. 2021. Characterization of spoilage bacterial communities in chilled duck meat treated by kojic acid. Food Sci Hum Well 10:72-77.

Ingram M, Dainty RH. 1971. Changes caused by microbes in spoilage of meats. J Appl Bacteriol 34:21-39.

Ji X, Hou C, Zhang X, Han L, Yin S, Peng Q, Wang M. 2019. Microbiome-metabolomic analysis of the impact of Zizyphus jujuba cv. Muzao polysaccharides consumption on colorectal cancer mice fecal microbiota and metabolites. Int $\mathrm{J}$ Biol Macromol 131:1067-1076.

Kemp PF, Aller JY. 2004. Bacterial diversity in aquatic and other environments: What 16S rDNA libraries can tell us. FEMS Microbiol Ecol 47:161-177.

Kulawik P, Özoğul F, Glew R. 2013. Quality properties, fatty acids, and biogenic amines profile of fresh tilapia stored in ice. 
J Food Sci 78:S1063-S1068.

Lee H, Kim MS, Lee WH, Cho BK. 2018. Determination of the total volatile basic nitrogen (TVB-N) content in pork meat using hyperspectral fluorescence imaging. Sensor Actuat B: Chem 259:532-539.

Li N, Zhang Y, Wu Q, Gu Q, Chen M, Zhang Y, Sun X, Zhang J. 2019a. High-throughput sequencing analysis of bacterial community composition and quality characteristics in refrigerated pork during storage. Food Microbiol 83:86-94.

Li Q, Zhang L, Luo Y. 2018. Changes in microbial communities and quality attributes of white muscle and dark muscle from common carp (Cyprinus carpio) during chilled and freeze-chilled storage. Food Microbiol 73:237-244.

Li X, Li C, Ye H, Wang Z, Wu X, Han Y, Xu B. 2019b. Changes in the microbial communities in vacuum-packaged smoked bacon during storage. Food Microbiol 77:26-37.

Li Y, Tang X, Shen Z, Dong J. 2019c. Prediction of total volatile basic nitrogen (TVB-N) content of chilled beef for freshness evaluation by using viscoelasticity based on airflow and laser technique. Food Chem 287:126-132.

Liang C, Zhang D, Zheng X, Wen X, Yan T, Zhang Z, Hou C. 2021. Effects of different storage temperatures on the physicochemical properties and bacterial community structure of fresh lamb meat. Food Sci Anim Resour 41:509-526.

Liu H, Hou C, Li N, Zhang X, Zhang G, Yang F, Zeng X, Liu Z, Qiao S. 2019. Microbial and metabolic alterations in gut microbiota of sows during pregnancy and lactation. FASEB J 33:4490-4501.

Lund BM, Baird-Parker TC, Gould GW. 2000. Microbiological safety and quality of food. vol. 1. Springer Science \& Business Media, Gaithersburg, MD, USA.

Magoč T, Salzberg SL. 2011. FLASH: Fast length adjustment of short reads to improve genome assemblies. Bioinformatics 27:2957-2963.

Marino R, Albenzio M, della Malva A, Muscio A, Sevi A. 2015. Nutritional properties and consumer evaluation of donkey bresaola and salami: Comparison with conventional products. Meat Sci 101:19-24.

MaršićLučić J, Tudor M, Šćekić V. 2008. Effect of defrosting on quantity of volatile amines in stored sardines and herring used for tuna fattening. J Appl Ichthyol 24:81-84.

Mohareb F, Iriondo M, Doulgeraki AI, Van Hoek A, Aarts H, Cauchi M, Nychas GJE. 2015. Identification of meat spoilage gene biomarkers in Pseudomonas putida using gene profiling. Food Control 57:152-160.

Na S, Kim JH, Jang HJ, Park HJ, Oh SW. 2018. Shelf life extension of Pacific white shrimp (Litopenaeus vannamei) using chitosan and $\varepsilon$-polylysine during cold storage. Int J Biol Macromol 115:1103-1108.

Nychas GJE, Skandamis PN, Tassou CC, Koutsoumanis KP. 2008. Meat spoilage during distribution. Meat Sci 78:77-89.

Parlapani FF, Verdos GI, Haroutounian SA, Boziaris IS. 2015. The dynamics of Pseudomonas and volatilome during the spoilage of gutted sea bream stored at $2^{\circ} \mathrm{C}$. Food Control 55:257-265.

Pfaffl MW, Riedmaier-Sprenzel I. 2018. New surveillance concepts in food safety in meat producing animals: The advantage of high throughput 'omics' technologies: A review. Asian-Australas J Anim 31:1062-1071.

Polidori P, Vincenzetti S, Cavallucci C, Beghelli D. 2008. Quality of donkey meat and carcass characteristics. Meat Sci $80: 1222-1224$.

Rodríguez-Calleja JM, Patterson MF, García-López I, Santos JA, Otero A, García-López ML. 2005. Incidence, radioresistance, and behavior of Psychrobacter spp. in rabbit meat. J Food Prot 68:538-543.

Säde E, Penttinen K, Björkroth J, Hultman J. 2017. Exploring lot-to-lot variation in spoilage bacterial communities on commercial modified atmosphere packaged beef. Food Microbiol 62:147-152.

Saewa SA, Khidhir ZK, Al Bayati MH. 2021. The impact of storage duration and conditions on the formation of biogenic 
amines and microbial content in poultry meat. Iraqi J Vet Sci 35:183-188.

Shaw BG, Latty JB. 1982. A numerical taxonomic study of Pseudomonas strains from spoiled meat. J Appl Bacteriol 52:219228.

Stellato G, La Storia A, De Filippis F, Borriello G, Villani F, Ercolini D. 2016. Overlap of spoilage-associated microbiota between meat and the meat processing environment in small-scale and large-scale retail distributions. Appl Environ Microbiol 82:4045-4054.

Stellato G, Utter DR, Voorhis A, De Angelis M, Murat Eren A, Ercolini D. 2017. A few Pseudomonas oligotypes dominate in the meat and dairy processing environment. Front Microbiol 8:264.

Van Reckem E, De Vuyst L, Weckx S, Leroy F. 2021. Next-generation sequencing to enhance the taxonomic resolution of the microbiological analysis of meat and meat-derived products. Curr Opin Food Sci 37:58-65.

Wang G, Li Q, Tang W, Ma F, Wang H, Xu X, Qiu W. 2021. AprD is important for extracellular proteolytic activity, physicochemical properties and spoilage potential in meat-borne Pseudomonas fragi. Food Control 124:107868.

Wang H, Luo Y, Huang H, Xu Q. 2014. Microbial succession of grass carp (Ctenopharyngodon idellus) filets during storage at $4^{\circ} \mathrm{C}$ and its contribution to biogenic amines' formation. Int J Food Microbiol 190:66-71.

Wang J, Fang J, Wei L, Zhang Y, Deng H, Guo Y, Hu C, Meng Y. 2019. Decrease of microbial community diversity, biogenic amines formation, and lipid oxidation by phloretin in Atlantic salmon fillets. LWT-Food Sci Technol 101:419-426.

Xiao X, Dong Y, Zhu Y, Cui H. 2013. Bacterial diversity analysis of Zhenjiang Yao meat during refrigerated and vacuumpacked storage by 454 pyrosequencing. Curr Microbiol 66:398-405.

Yang X, Zhu L, Zhang Y, Liang R, Luo X. 2018. Microbial community dynamics analysis by high-throughput sequencing in chilled beef longissimus steaks packaged under modified atmospheres. Meat Sci 141:94-102.

You J, Wu G, Ren F, Chang Q, Yu B, Xue Y, Mu B. 2016. Microbial community dynamics in Baolige oilfield during MEOR treatment, revealed by Illumina miseq sequencing. Appl Microbiol Biotechnol 100:1469-1478.

Zhang Y, Yao Y, Gao L, Wang Z, Xu B. 2018. Characterization of a microbial community developing during refrigerated storage of vacuum packed Yao meat, a Chinese traditional food. LWT-Food Sci Technol 90:562-569.

Zhao F, Zhou G, Ye K, Wang S, Xu X, Li C. 2015. Microbial changes in vacuum-packed chilled pork during storage. Meat Sci 100:145-149.

Zheng R, Xu X, Xing J, Cheng H, Zhang S, Shen J, Li H. 2020. Quality evaluation and characterization of specific spoilage organisms of Spanish mackerel by high-throughput sequencing during $0^{\circ} \mathrm{C}$ cold chain logistics. Foods 9:312.

Zhou C, Wang J, Li R, Ye K. 2020. High-throughput sequencing analysis of the bacterial community for assessing the differences in extraction methods of bacteria separation from chilled pork. LWT-Food Sci Technol 134:110213. 